\title{
Unconscious Learning. Conditioning to Subliminal Visual Stimuli
}

\author{
Juan P. Núñez ${ }^{1}$ and Francisco de Vicente ${ }^{2}$ \\ ${ }^{1}$ University Pontificia Comillas of Madrid \\ ${ }^{2}$ University Complutense of Madrid
}

\begin{abstract}
The role of consciousness in Pavlovian conditioning was examined in two experiments in which visually masked neutral words were used as the conditioned stimuli (CS) and an electric shock as the unconditioned stimulus (US). The inter-stimulus interval (ISI) was established individually. A detection threshold was used in Experiment 1 and an identification threshold in Experiment 2. The primary dependent variable was the skin conductance response (SCR). Results showed that the conditioned response (CR) was acquired by $58 \%$ of participants who perceived stimuli above the identification threshold, $50 \%$ of participants who perceived stimuli below the detection threshold, and $11 \%$ of participants who perceived stimuli below the identification threshold, but above the detection threshold. These results suggest that consciousness of the CS-US contingency is not a necessary condition for acquiring a CR of the autonomous nervous system (ANS). Keywords: Pavlovian conditioning, backward masking, subliminal perception, conscious and unconscious learning
\end{abstract}

\begin{abstract}
Se analizó el papel de la consciencia en el condicionamiento pavloviano mediante dos experimentos en los que se utilizaron, como estímulos condicionados (ECs), palabras neutras visualmente enmascaradas y, como estímulo incondicionado (EI), un shock eléctrico. El intervalo inter-estímulo se estableció individualmente. Se utilizó un umbral de detección en el Experimento 1 y un umbral de identificación en el Experimento 2. La principal variable dependiente fue la respuesta de conductancia de la piel. Los resultados mostraron que la respuesta condicionada $(\mathrm{RC})$ fue adquirida por el $58 \%$ de los sujetos que percibieron los estímulos por encima del umbral de identificación, por el 50\% de los sujetos que percibieron los estímulos por debajo del umbral de detección y por el $11 \%$ de los sujetos que percibieron los estímulos por debajo del umbral de identificación, pero por encima del umbral de detección. Estos resultados sugieren que la conciencia de la contingencia EC-El no es condición necesaria para adquirir una RC del sistema nervioso autónomo. Palabras clave: condicionamiento pavloviano, enmascaramiento hacia atrás, percepción subliminal, aprendizaje consciente e inconsciente
\end{abstract}

This paper is based on Juan P. Núñez's Doctoral Disseratation.

Correspondence concerning this article should be addressed to either Juan P. Núñez, Departamento de Psicología, Facultad de Ciencias Sociales y Humanas, Universidad Pontificia de Comillas de Madrid, C/ Universidad de Comillas nº 3, 28049 Madrid (Spain), or to Francisco de Vicente, Departamento de Psicología Básica I, Facultad de Psicología, Universidad Complutense de Madrid, Campus de Somosaguas, 28223 Madrid (Spain). E-mail: jnunez@chs.upco.es or fvicente@sis.ucm.es 
The role of awareness in human learning has been studied in Pavlovian conditioning, as well as in instrumental conditioning, and continues to be a controversial issue. Whereas some authors argue that conditioning cannot occur without the intervention of consciousness (Davey, 1992a), others maintain that its presence is not necessary (Berry, 1994). One possible explanation for this controversy could be the diversity of the methods used to prevent consciousness, so that it is difficult to compare the results from different studies. Three methodological problems tend to be addressed in this type of study: (a) how to prevent the participant from being aware of relevant contingency, (b) how and when to measure consciousness, and (c) the interference between conscious and unconscious activity.

With regard to the first methodological problem, techniques employed to prevent consciousness vary greatly and have different degrees of efficiency. They include: (a) generating false expectations in participants, (b) conditioning instrumental responses unnoticeable to participants, (c) implicit learning techniques, (d) working with participants in altered states of consciousness, (e) working with participants who have cerebral alterations, and (f) presenting the CS with subliminal perceptual techniques.

Generating false expectations in participants. This technique has been used in instrumental conditioning of simple responses with contradictory results. Whereas Svartdal and Mortensen (1993) found positive results (an instrumental response appeared without signs of consciousness of relevant contingency), Shanks and Dickinson (1991) did not (a conditioned response [CR] did not appear, or there were signs of consciousness). Some authors question the efficiency of this technique because the participants' possible false expectations or other perceptions of the task could be useful to predict the appearance of the reinforcement stimulus (Shanks, Green, \& Kolodny, 1994).

Conditioning instrumental responses unnoticeable to participants (small muscular contractions, cortical potentials, etc.). Although several authors have found positive results (Hefferline \& Keenan, 1961), this technique raises a doubt over whether perception of reinforcement stimuli could induce the acquisition of conscious responses that influence the unnoticeable responses in the expected direction.

Implicit learning techniques. In a set of techniques known as implicit learning-instrumental conditioning of complex responses-(e.g., Shanks, et al., 1994), the success of the task depends on a complex rule for concealing the responsereinforcement relationship from the participant. Examples of these tasks include classifying words according to an artificial grammar, predicting the appearance of a stimulus in a sequence, or controlling a complex system. In recent years, this approach has been most fruitful, despite discrepancies among authors. The differences between those who found positive results (Lee, 1995; Turner \& Fischler, 1993) and those who obtained negative results (Meulemans \& Van der Linder, 1997; Perruchet, Gallego, \& Pacteau,
1992; Shanks et al., 1994) lie in the complexity of the rule used, as greater complexity implies less likelihood of participants being conscious of the relationship between response and reinforcement. Another problem that emerges is that, although the rule will be learned unconsciously, signs of consciousness could appear because participants know the stimuli presented, the responses, and their effects, enabling them, with practice, to deduce and verbalize some of the rule's keys (Broadbent, Fitzgerald, \& Broadbent, 1986; Hayes \& Broadbent, 1988).

Working with participants in altered consciousness states (dream, coma, anesthesia, hypnosis, etc.). The studies that have used this technique also obtained contradictory results. Thus, some authors found positive results (Jelicic, Bonke, Wolters, \& Phaf, 1992), whereas others found negative results (Ghoneim, Block, \& Fowles, 1992). A number of authors maintain that this technique does not guarantee that participants do not experience some moment of consciousness during task performance (Andrade, 1995).

Working with participants who have cerebral alterations (visual agnosia, amnesia, etc.). This approach allows researchers to know which neurological processes are related to the conscious and unconscious aspects of assigned tasks (Bechara et al., 1995; Bechara, Damasio, Tranel, \& Damasio, 1997; LeDoux, 1990, 1996; Tranel \& Damasio, 1993). In addition, positive results have been found when eliciting CRs with amnesiacs who did not remember either the conditioned stimulus-unconditioned stimulus (CS-US) association or the learning context (Daum, Channon, \& Canavar, 1989; Gabrieli et al. 1995). However, this technique is problematic because available individuals are scarce, and it is always dubious whether the results can be generalized to healthy participants.

Presenting CSs with subliminal perceptual techniques. The use of these techniques arguably solves some of the problems that emerge with the previous techniques. Their efficiency for preventing the perception of CSs and for eliciting, without consciousness, a previously-acquired CR has been studied in depth (Corteen \& Wood, 1972; Lazarus \& Mc Cleary, 1951; Wong, Shevrin, \& Williams, 1994). However, these techniques have seldom been employed during the $\mathrm{CR}$ acquisition phase, except in research on evaluative conditioning (Baeyens, Hermans, \& Eelen, 1993; De Houwer, Hendrickx, \& Baeyens, 1997; Levey \& Martin, 1975). The results obtained in these studies have not always been positive (Cohen, 1964; Davey, 1994; Shanks \& Dickinson, 1990). Critics of these techniques tend to point out visual masking as the most reliable technique because it enables an objective measure of consciousness and one that is simultaneous with task performance, as participants must pay attention to relevant stimuli (Holender, 1986).

The second methodological problem is when and how to measure consciousness. If consciousness is measured at the end of the acquisition phase, participants may forget or mix up contingencies, or answer negatively because they are uncertain due to the time that has elapsed (Holender, 
1986; Shanks et al., 1994). On the other hand, if consciousness is measured during the acquisition phase, the researcher's questions may cause the participant to pay attention to relevant contingencies that had hitherto gone unnoticed (Greenspoon, 1963).

With regard to how to measure consciousness, several authors favor objective measures over participative ones. Even so, there are discrepancies about how to interpret which results are the consequence of conscious information processing and which are the consequence of unconscious processing (Holender, 1986; Reingold \& Merikle, 1988).

The third methodological problem is the interference between conscious and unconscious activity. Unconscious learning cannot be deemed possible while working with consciously-perceived stimuli, because consciousness is participating, albeit in a quite passive way; or at least, it is not possible to ensure that unconscious learning will be the same when consciousness does not participate in the process. Conscious perception fosters association among stimuli, as only the stimulus that has been selected from among all those activated at the unconscious level breaks into the consciousness (Marcel, 1983b). Thus, it would be appropriate to inquire if any of the potential unconscious conditionings would have been as quick if all the semantic elements related to each stimulus used during the task had had to be kept activated. In addition, as unconscious processing works basically in parallel, CR acquisition could have been supported, as all stimuli are processed sequentially by consciousness and, hence, it is easier to establish the CS-US contingency. That is, whereas it is not guaranteed that the unconscious system is capable of learning by itself, it would be premature to relegate to second place, the role of consciousness in this type of procedure. On the other hand, if consciously-controlled motor responses are used (Grant, 1973; Montare, 1992), participants can deduce the relevant contingency by analyzing their behavior, so that learning may seem conscious when it was in fact achieved unconsciously (Baer \& Fuhrer, 1982).

Contradictory results can also be ascribed to interference between conscious and unconscious processes. Thus, when consciousness is not prevented at all, or when participants do not assume some degree of passivity during the task, the effects of unconsciously-processed information tend to be inhibited, both in subliminal perception (Dixon, 1981; Landis, Christen, \& Graves, 1992; Marcel, 1983a; Snodgrass, Shevrin, \& Kopka, 1993; Van Selst \& Merikle, 1993) and in conditioning (Baron \& Galizio, 1983; Berry 1994; Lowe, 1983; Ross, Ferreira, \& Ross, 1974; Shimoff, Catania, \& Matthews, 1981; Svartdal, 1992).

The dissociation effect paradigm (Debner \& Jacoby, 1994; Merikle, Joordens, \& Stolz, 1995) has solved the interference problem in perceptual and memory tasks due to the control that can be exercised over consciouslyprocessed information and the impossibility of controlling unconsciously-processed information. However, this technique is not applicable to conditioning, as participants cannot be requested to not associate contingently-presented stimuli; nor can their autonomous nervous systems (ANS) be prevented from responding to the $\mathrm{CS}+$. If they are requested to not respond when the $\mathrm{CR}$ is controlled by the central nervous system, they may respond regardless of whether or not they perceive the relevant contingency.

Conditioning ANS responses to unconsciously-perceived CSs over which participants have no direct control, reduces the intervention of consciousness in the task as much as possible, as well as alleviating the problem of interference between conscious and unconscious activity.

Öhman is indisputably one of the leading authors in this field. Using visually-masked fear-relevant stimuli (snakes, spiders, or pictures of angry faces) as the CS+, an electric shock as the US, and skin conductance response (SCR) as the CR, Öhman and his team examined both the possibility of eliciting, without participants' consciousness, previous consciously-acquired CRs (Öhman \& Soares, 1993; Soares \& Öhman, 1993a, 1993b), and the possibility of acquiring CRs without consciousness (Esteves, Parra, Dimberg, \& Öhman, 1994; Öhman, 1998; Öhman \& Soares, 1998). The results of this research seem to confirm that both elicitation and acquisition of CRs without consciousness are possible only if fear-relevant stimuli are used as the CS. Nevertheless, the methodology used in most cases does not guarantee the unconscious perception of stimuli stipulated by some authors (Cheesman \& Merikle, 1984; Holender, 1986; Merikle, 1982; Reingold \& Merikle, 1988). Although Esteves and Öhman (1993) attempted to validate their method, they did not do so by gradually reducing the exposition times until reaching the perceptual threshold of each participant, nor did they carry out a sufficient number of trials, and some signs of stimulus discrimination appeared when objective measures of consciousness were taken, so that certain doubts about their results persist. They also tended to use identification tasks as a measure of consciousness, thus preventing unconscious processing of neutral stimuli (Dagenbach, Carr, $\&$ Wilhelmsen, 1989). Moreover, they used the same number of reinforced trials for the CS+ and CS- during the acquisition phase, leading to the conclusion that masked fear-relevant stimuli facilitate CR acquisition sooner than do neutral stimuli; however, it cannot be asserted that the CR cannot be acquired from masked neutral stimuli. It may simply be necessary to perform more trials in order to achieve this.

Our objective was to test the hypothesis that considers consciousness of the CS-US contingency a necessary condition for CR acquisition by the ANS in human Pavlovian conditioning using masked neutral visual stimuli as the CS. The presentation threshold was calculated so that it met all the requirements established by reviewers of unconscious perception (Cheesman \& Merikle, 1984; Holender, 1986; Merikle, 1982; Reingold \& Merikle, 1988). The measurement of consciousness used throughout the experimental phases was simultaneous with the appearance of stimuli. 


\section{Experiment 1}

In this experiment, visually-masked words were used as the CS and the presentation threshold was established individually. Differential trace conditioning was performed during a large number of trials using a shock as the aversive US. Each response to the CS+ was compared with the average of the responses to the CS- in order to detect the $\mathrm{CR}$ as soon as possible. A restrictive $\mathrm{CR}$-acquisition criterion was also established to prevent spontaneous SCRs of high amplitude as well as the $\mathrm{CS}+$ from being considered the $\mathrm{CR}$.

\section{Method}

The original group was made up of 43 volunteer students (11 male and 32 female), from a first-year Psychology course, with a mean age of 18.7 years (range 17-28 years). They received credits in the subject "Psychology of Learning" for participating in the experiment. All participants had normal vision or vision that had been corrected to normal. Seven participants were excluded or dropped out for various reasons, so that the final group included 36 participants ( 9 male and 27 female). Eighteen participants were assigned, at random, to each experimental group.

\section{Apparatus and Material}

The experiment was carried out in two contiguous Faraday cabins in the Psychology Faculty Laboratory at the Complutense University of Madrid. Both cabins were kept dimly lit and at a constant temperature $\left(21 \pm 2^{\circ} \mathrm{C}\right)$.

Stimuli were presented by means of a tachistoscope (Gerbrands, model G1130-lamp driver 403). The distance between the surface of the stimulus and the participant's eyes was $78.74 \mathrm{~cm}$ (31 inches). Maximum vision angle was approximately $5^{\circ}$. The mask was placed in one field, the blank card in the second, and in the third field, the two words used as the CS were presented alternately and at random to each group. A trained assistant changed the cards when appropriate. Before each trial, a light indicated the beginning of a stimulus sequence. The lighting for each field was constant during the experiment (mask field $=2.6 \mathrm{~cd} / \mathrm{m}^{2}$; blank field $=1 \mathrm{~cd} / \mathrm{m}^{2}$; word field $=1.1 \mathrm{~cd} / \mathrm{m}^{2}$ ).

The SCR was recorded with a polygraph (Lafayette model Li-76400 type B 7603-1A). Silver-chromed electrodes were placed on the middle phalanxes of the index and ring fingers of the non-dominant hand, with the middle finger between them to prevent the electrodes from coming into contact accidentally. Beforehand, the fingers were cleaned with alcohol and a fine coat of conducting gel was applied (Venables \& Christie, 1980).

An audio generator (VIZ W-504B/441) and amplifier (Lafayette model Li-15010) emitted the tone that served as a signal for participants to press the correct key on the keyboard placed near their dominant hand. The keyboard was specifically made for this experiment, having only two keys: Word/Blank. An electric shock generator (Mark 100) was used to produce the US. Experimental events were controlled by a PC running specially-designed software.

Words used as the CS were printed in black on a white background, each letter was $12 \mathrm{~mm}$ high and 8-9 mm wide, and the strokes were $2 \mathrm{~mm}$ thick. The two words that were used ("Magnesio" [Magnesium] and "Locuacidad" [Loquaciousness]) have a usage frequency of 1 in Spanish according Mighetto and Rosengren (1984), and of 0 according to Alphonse and Rodríguez (1964). The two words each have only one meaning according to the Royal Spanish Academy (1994), and are between 6 and 10 letters long. The mask pattern was ten letters long (XOXOXOXOXO).

\section{Variables and Design}

A $2 \times 2$ factorial design, with repeated measures in the last factor, was employed. The first factor was a presentation of the CS, with two levels: above the conscious threshold (conscious group) or below the conscious threshold (unconscious group). The second factor was the word-shock relationship, with two levels: associated (CS+) or not associated (CS-) with a shock (US). Within each group, the word that acted as the CS+ was balanced, with one word acting as the CS+ for $50 \%$ of the participants and the other word for the rest.

The dependent variable was acquisition of the conditioned response (CR), measured by two approaches. First, the SCR amplitude during the $4 \mathrm{~s}$ subsequent to the $\mathrm{CS}+$ should be significantly greater than the mean amplitude of responses to the CS-, according to the inequality of Chebychev (1874) with $K=2.23$ (see Sachs, 1969). Likken and Venables' (1971) and Likken's correction (1972) were applied to the SCR before statistical analysis, and all calculations were updated each time a new maximum value of the SCR appeared. Second, it was considered that the CR had been acquired when the amplitude of two SCRs following the $\mathrm{CS}+$ was significantly greater than the mean amplitude following the CS- according to the first approach, and provided that between these two SCRs not more than one CS+ had appeared with an insignificant $\mathrm{SCR}^{1}$.

1 With this CR acquisition criterion, the maximum probability that the CR could be acquired randomly was $p=.000021$ for Experiment 1 and $p=.000087$ for Experiment 2. (With only the first approach, $p=.013$ for normal distributions and $p=.1$ for the rest of the distributions. Obviously, a higher value for $K$ had reduced the strength of the comparison to practically zero; moreover, a response of more than three standard deviations above the SCR average is not expected with a non-painful stimulus). 
Other dependent variables were measured to detect differences between conscious and unconscious conditioning: the number of trials needed to acquire the CR and regularity of CR acquisition (two or three consecutive trials with the $\mathrm{CS}+$ ).

The possible effect of the shock on detection of the CS+ was measured by the percentage of correct answers to that stimulus. It must be taken into account that the presence of the CS+ could be discriminated effectively without the total percentage of correct answers being above random.

\section{Procedure}

Before the experimental stage, all participants completed several tests to measure personality (16PF; Cattell, 1949), intelligence (Domino-48 Intelligence Test; Anstey \& Pichot, 1955), attention (Test de percepciones y diferencias - Caras [Test of Perceptions and Differences-Faces]; Thurstone \& Yela, 1968), and locus of control (LUCAM; Pelechano \& Baguena, 1983).

The experimental stage consisted of three phases: the threshold establishment phase, the CR acquisition phase, and the extinction phase.

Threshold establishment phase. First, participants experienced a period of habituation to experimental conditions. During this period of approximately 10-15 min, participants received initial instructions and underwent a brief training period of 20 trials to check whether they had understood the task, to familiarize themselves with the apparatus and laboratory conditions and to stabilize their SCR. Subsequently, the threshold establishment phase began, in which the visual perceptual threshold was calculated for each participant by variations in the inter-stimulus interval (ISI). The approximate duration of this phase was 90-120 min. Stimulus presentation was random. A height-adjustable chair was used to guarantee that vision was centered on the screen. At the beginning of each trial, a light in the center of the screen signaled participants to pay attention. Instructions were read aloud to each participant. They were told they must respond only after hearing a low tone through their earphones. This tone sounded five seconds after the mask went off. This guaranteed that recording of the SCR would not be affected by movement to press a key (although this movement was carried out with the hand that was not connected to the electrodes), nor by the decision about which key to press (Lazarus \& McCleary, 1951). If participants did not respond within three seconds after the tone, or the response had not been recorded, a second, longer tone was emitted to remind them that they had to respond.

The duration of the card (Word or Blank) was $10 \mathrm{~ms}$, and the mask lasted $50 \mathrm{~ms}$. The inter-trial interval was varied, with an average of $20 \mathrm{~s}$ (range 15-25s). Duration of the interval allowed the SCR to return to its initial level (see Venables \& Christie, 1980).

The perceptual threshold of each participant was fixed when accuracy of responses was not above the probability of responding correctly at random. The procedure used to calculate this was that found to be the most rigorous and effective by Dagenbach et al. (1989), and it also fulfilled all the conditions established by Merikle (1982). The participants' task consisted of emitting detection judgments about the presence or absence of a word on the screen. That is, participants simply had to differentiate whether the flash of light corresponded to a blank screen or to a screen with a word by pressing the appropriate key (Blank/Word) on the keyboard with the hand controlled by the dominant hemisphere.

Participants were informed about the frequency with which the stimuli would appear (50\% Blanks and 50\% Words, of which $25 \%$ corresponded to one word and $25 \%$ to the other), and they were requested to try to maintain a similar distribution in their responses. For this purpose, they were informed about the number of each type of responses they had given after each trial. They were told that when they thought they were responding at random, they should try to adjust the frequency of their responses to the real appearance-frequency of the stimuli, and that they should always give a response.

The experiment began with blocks of 8 trials ( 4 blanks and 4 words) distributed at random, and the initial duration of the ISI $(50 \mathrm{~ms})$ was reduced according to the following criteria:

1. If the number of correct responses was $\geq 5$, the ISI was shortened by $5 \mathrm{~ms}$ (until $10 \mathrm{~ms}$ was reached, after which it was reduced by $2 \mathrm{~ms}$ each time); then the process started over again. If the number of correct responses was $\leq 4$, a block of 20 trials was presented under the same conditions.

2 . If the number of correct responses in this block was $\geq 12$, the ISI was reduced and the process began over again, and if the number of correct responses was $<12$, this ISI duration was established as the participant's perceptual threshold.

3. Final checking: Two blocks of 20 trials were presented at the established ISI. In the first block, the task was also to emit detection judgments. If the number of correct responses was $\geq 12$, the ISI was reduced and the process began over again; if the number of correct answers was < 12 , the following block was presented. In this block, the task consisted of identifying words. Participants had to say out loud the word they thought they had seen when they responded "Word." Participants were requested to say the first word they thought of if they believed they were responding at random, which occurred in most cases. At the beginning of this block, the two words used up to that point were changed for different ones that the participants had not seen previously. If participants identified a word correctly, or if the number of correct responses was 12 in the detection judgments, the ISI was reduced and the process started over again; otherwise this phase ended.

Participants were informed about the level of accuracy of their responses after each block in order to maintain a high level of motivation and to enable them to distinguish the 


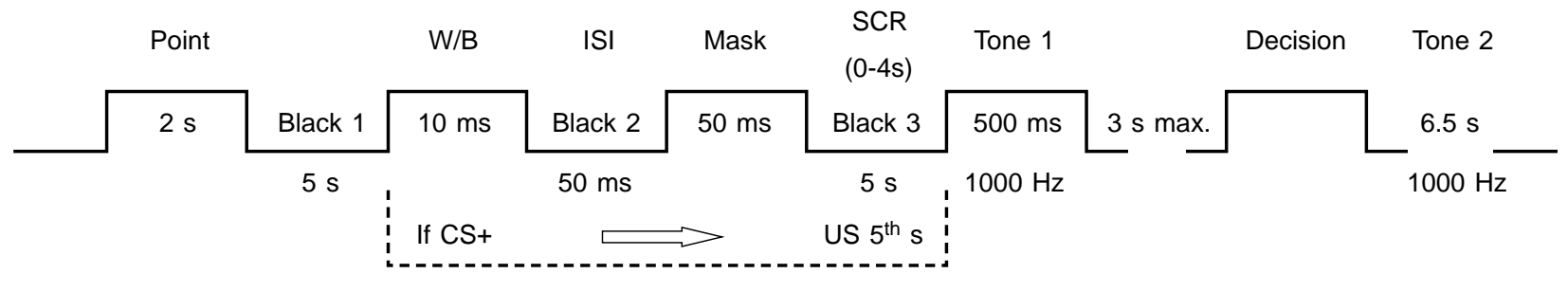

Figure 1. Sequence of stimulus presentation. Values under each element indicate its duration (s/ms) or its intensity (Hz). In the case of the ISI, its initial value appears. Each time the CS+ appeared, a shock was presented in the fifth second after the mask and when SCR recording was over.

correct criteria they had used to respond (Cheesman \& Merikle 1984). Although the presentation order of stimuli was random, the same stimulus could only appear a maximum of two times consecutively (Soares \& Öhman, 1993a, 1993b). Participants had a 5-10 min break after this phase.

CR acquisition phase. This phase also began with an adjustment phase lasting roughly $15 \mathrm{~min}$. This period was used to determine the intensity and duration of the US. The intensity of the shock (US) was established individually for each participant until a sensation reported as "clearly uncomfortable but not painful" was evoked. In addition, participants were instructed to indicate, if necessary, a change in the shock intensity during the experiment. Next, they were reminded that they were free to leave the experiment at any stage without any negative consequences to them. Lastly, they were informed that the shocks would be administered at random and that they should not use this as criterion to respond. The participant's task was detection judgments as in the first phase (in accordance with the criteria established by Cheesman and Merikle, 1984) and they had another training period of 20 trials to become familiar with the electrode and shock.

Next, participants completed a maximum of 5 blocks of 20 trials. The maximum duration of this phase was approximately $1 \mathrm{hr}$. The word used as the CS+ was associated with the US $100 \%$ of the time. Stimuli were presented below or above the perceptual threshold according to the conscious level attributed to each group. Stimuli were presented at the ISI established for each participant in the unconscious group and at $50 \mathrm{~ms}$ in the conscious group (except for two participants in this group, to whom stimuli were presented at $100 \mathrm{~ms}$ because their thresholds were $50 \mathrm{~ms}$ and $45 \mathrm{~ms}$, respectively).

The number of correct responses could be measured trialby-trial because the task consisted of detection judgments, as in the first phase. All participants in the unconscious group who responded correctly above random were identified and removed from the group immediately, so that nonconsciousness was guaranteed for as long as possible.

The sequence of stimulus presentation was similar to that of the first phase, adhering to the guidelines established by Cheesman and Merikle (1984). The only difference was the presentation of the US $4 \mathrm{~s}$ after the CS+ (Marcos, 1997).
This time period was used to record the SCR from the first interval (FIR) (Prokasy \& Ebel, 1967).

Software was designed to finalize this phase when the participant reached the $\mathrm{CR}$ acquisition criterion in order to ensure that all participants went on to the extinction phase with the same index of CR reinforcement.

Extinction phase. Only participants who reached the CR acquisition criterion before 100 trials carried on to this phase. The shocker was turned off at the beginning of this phase and participants were informed about US withdrawal to prevent the experiment from being extended unnecessarily (Davey, 1992b). There are some studies in which the CR is maintained even when participants know that the US is absent (Fuhrer \& Baer, 1980; Wong et al., 1994). This phase ended when the CR failed to appear in the last three trials with the CS+.

Finally, participants answered a series of questions to detect possible biases that could have affected the development of the experiment and to measure the subjective consciousness of the CS-US contingency.

\section{Results}

\section{CR Acquisition}

The data showed that $50 \%$ of the participants who remained working at a non-conscious level, and $11 \%$ of the participants who worked at a conscious level, reached the $\mathrm{CR}$ acquisition criterion. The difference in the percentage of participants who reached the $\mathrm{CR}$ acquisition criterion under each separate condition was statistically significant $(a \leq .05)$ according to Fisher's non-parametric exact onetail test, $p=.05$.

Table 1

Experiment 1. Percentage of Participants Who Did and Did Not Reach the CR Acquisition Criterion

\begin{tabular}{lcc}
\hline \multirow{2}{*}{ Group } & \multicolumn{2}{c}{ CR Acquisition } \\
\cline { 2 - 3 } & Yes & No \\
\hline Conscious & $11 \%(n=2)$ & $89 \%(n=16)$ \\
Unconscious & $50 \%(n=4)$ & $50 \%(n=4)$ \\
\hline
\end{tabular}




\section{CR Extinction}

There were no statistically significant differences in CR extinction between each kind of conditioning, because all participants who reached the $\mathrm{CR}$ acquisition criterion stopped responding to the $\mathrm{CS}+$ during the first three trials in which this stimulus appeared in this phase.

\section{Variability and Stability of Visual Perceptual Threshold}

Individual variability of the perceptual threshold differed between the participants who had to be rejected by reducing ISI to $0 \mathrm{~ms}$ and the participants who did not discriminate above random with ISI $=50 \mathrm{~ms}$ (for final participants: $M$ $=22 \mathrm{~ms}, S D=14 \mathrm{~ms}$, Max. $=50 \mathrm{~ms}$, Min. $=5 \mathrm{~ms}, N=$ 36). The stability of the perceptual threshold was very poor. Fifty-five percent of the participants from the unconscious group were excluded in the CR acquisition phase because their perception was above random.

\section{Stimulus Discrimination and CR Acquisition}

Participants who remained working at a non-conscious level maintained a below-random $\mathrm{CS}+$ detection level. No differences were found between participants who reached the $\mathrm{CR}$ acquisition criterion and those who did not for perceptual discrimination (Mann-Whitney's $U=5.5, p=.48$, for percentage of correct responses, $49 \%$ and $47 \%$, respectively, and $U=6, p=.68$, for percentage of CS+ detection, $40 \%$ and $47 \%$, respectively). Two of the participants from the unconscious group, who reached the CR acquisition criterion, detected a word once in the presence of two CSs + that triggered the CRs with which they reached the $\mathrm{CR}$ acquisition criterion (50\% accuracy), and another two participants responded that there was a blank on the screen in both trials ( $0 \%$ accuracy). Thus, even in these particular trials, participants who remained working at a non-conscious level and reached the $\mathrm{CR}$ acquisition criterion did not perceive the CS+.

Participants from the conscious group who reached the $\mathrm{CR}$ acquisition criterion had considerably higher percentages of correct responses and $\mathrm{CS}+$ detection than the rest of the participants from their group $(U=0, p=.013$, for percentage of correct responses, $96 \%$ and $71 \%$, respectively, and $U=$ $0, p=.013$, for percentage of CS+ detection, $97 \%$ and $72 \%$, respectively). In addition, they responded correctly in the presence of two CSs+ that triggered the CRs, at which level they reached the $\mathrm{CR}$ acquisition criterion.

\section{Discussion}

These results indicate that it is possible to condition the CR without participants' consciousness of the CS-US contingency. The low percentage of participants from the conscious group who reached the $\mathrm{CR}$ acquisition criterion suggests that the CRs of the ANS are more easily acquired than stimuli not perceived consciously, unless a very restrictive conscious threshold (detection judgments) is used. Participants from the conscious group simply discriminated whether or not there was something on the screen, but they were unable to identify what it was and, as a result, could barely capture the CS-US relationship.

Dagenbach et al. (1989) postulate that the task used to measure consciousness could inhibit priming effects, and could therefore also affect conditioning. This is why identification judgments were used to measure consciousness in the second experiment, whose design was similar to that of Experiment 1.

Many studies have found that only when participants adopt a passive attitude during the task, do the effects of unconsciously processed information appear (Dagenbach et al., 1989; Dixon 1981; Landis et al., 1992; Marcel, 1983a, 1983b; Snodgras et al., 1993; Van Selst \& Merikle, 1993). Identification judgments force participants to offer responses about what they see and, as they see something, they remain alert in an attempt to identify what is presented to them. Staying alert prevents unconscious information from being used in this situation. In these cases, the accuracy of consciously-generated hypotheses will determine whether the CR can be acquired or not. Participants who perceive clearly will be more accurate in their expectations, and will acquire the CR more easily. Participants who do not perceive clearly will generate incorrect hypotheses, and will find it more difficult to reach the $\mathrm{CR}$ acquisition criterion.

\section{Experiment 2}

\section{Method}

\section{Participants}

The original group consisted of 29 volunteer students (4 male and 25 female) from the first-year Psychology course, with a mean age of 18 years (range 17-25). Participants were different from those who took part in Experiment 1, but had similar characteristics. As five participants were excluded or dropped out for various reasons, the final group numbered 24 (20 female and 4 male), and these were divided at random into two experimental groups (12 participants per group).

\section{Apparatus and Material}

The same apparatus was employed as in Experiment 1.

\section{Experimental Design}

The same conditions were maintained as in Experiment 1 , except that the task involved identification judgments. 


\section{Procedure}

All phases were identical to those in Experiment 1, except for the thresholds establishment phase. This phase lasted approximately $90 \mathrm{~min}$. The lighting of the Blank (Non-word) field was varied to match the Word field, as this time words were presented in both fields. The fields were as follows: Non-word field $=1.1 \mathrm{~cd} / \mathrm{m}^{2}$, Word field $=$ $1.1 \mathrm{~cd} / \mathrm{m}^{2}$, and Mask field $=2.6 \mathrm{~cd} / \mathrm{m}^{2}$.

Participants were informed about the appearance frequency of words: $25 \%$ for Word 1 (Magnesio), 25\% for Word 2 (Locuacidad), 25\% for Non-word 1 (Mengisao), and 25\% for Non-word 2 (Lidocaduca). This time, the keyboard had three keys and participants were requested to press the " $\mathrm{M}$ " key if they thought they had seen Word 1, the "L" key if they thought they had seen Word 2, and the "NOT" key if they thought that they had seen either of the non-words. Only identification judgments on words with meaning were considered correct or incorrect. When participants pressed the "NOT" key, they were not requested to identify which of the two non-words had been presented. Thus, the probability of obtaining correct responses at random was $50 \%$ and the frequency appearance of the CS+ in the second phase was 25\%, the same as in Experiment 1.

The sequence of stimulus presentation mirrored that of Experiment 1, but to enable the identification of words, the initial value of the ISI was $200 \mathrm{~ms}$ and, as the maximum number of correct responses was lower, the ISI was reduced as follows:

1. In blocks of eight trials, if the number of correct responses was $\geq 3$, the ISI was shortened by $5 \mathrm{~ms}$ (until 10 ms was reached, after which it was reduced by $2 \mathrm{~ms}$ each time) and the process began over again. If the number of correct responses was $\leq 3$, a block of 20 trials was presented under the same conditions.

2. If the number of correct responses in this block was $\geq 6$, the ISI was reduced and the process began over again. If the number of correct responses was $<6$, this ISI duration was established as the participant's perceptual threshold.

3. Final checking: Two blocks of 20 trials were presented at the established ISI. If the number of correct answers was $>6$ in either of the two blocks, the ISI was reduced and the process started again. If the number of correct responses was $\leq 6$ in both blocks, the participant passed to the next phase.

\section{Results}

\section{CR Acquisition}

The data showed that $10 \%$ of the participants who remained working at an unconscious level $(n=1)$ and $58 \%$ of the participants who worked at a conscious level $(n=7)$ reached the $C R$ acquisition criterion. The difference in the percentage of participants who reached the CR acquisition criterion under each condition was statistically significant $(\mathrm{a} \leq .05)$ according to Fisher's exact one-tail test, $p=.02$.
Table 2

Experiment 2. Percentage of Participants Who Did and Did Not Reach the CR Acquisition Criterion

\begin{tabular}{lcc}
\hline \multirow{2}{*}{ Group } & \multicolumn{2}{c}{ CR Acquisition } \\
\cline { 2 - 3 } & Yes & No \\
\hline Conscious & $58 \%(n=7)$ & $42 \%(n=5)$ \\
Unconscious & $10 \%(n=1)$ & $90 \%(n=9)$ \\
\hline
\end{tabular}

\section{CR Extinction}

All of the participants who reached the CR acquisition criterion ceased responding to the $\mathrm{CS}+$ during the first three trials in which this stimulus appeared in this phase.

\section{Variability and Stability of Perceptual Threshold}

Individual variability of the ISIs also differed among participants who had to be excluded, as the ISI was reduced to $0 \mathrm{~ms}$, or participants did not discriminate above random with an ISI $=200 \mathrm{~ms}$ (for final participants $M=36 \mathrm{~ms}, S D$ $=21 \mathrm{~ms}$, Max. = $100 \mathrm{~ms}$, Min. = $15 \mathrm{~ms}, N=24)$. The stability of the perceptual threshold was higher than in Experiment 1; only $16 \%$ of the participants from the unconscious group were excluded in the acquisition phase due to above-random perception.

\section{CR Acquisition and Stimulus Discrimination}

Participants who remained working at a non-conscious level maintained a below-random identification level of the $\mathrm{CS}+$. The only participant from this group who acquired the CR had a lower percentage of correct responses $(26 \%)$ and CS+ identification $(20 \%)$ than those obtained by the rest of participants from this group (33\% and 32\%, respectively). This data indicates that this individual's perception was poorer than that of the rest. Furthermore, this participant also failed to identify the CS+ in both of the trials in which the CRs appeared, at which level the CR acquisition criterion was reached.

In the conscious group, no statistically significant differences emerged between participants who reached the CR acquisition criterion and those who did not $(84 \%$ and $81 \%$, respectively, for percentage of correct responses, $U=$ $16.5, p=.87$; and $83 \%$ and $73 \%$, respectively, for CS+ identification, $U=10, p=.26$ ).

\section{Discussion}

Most participants who performed below the identification threshold did not reach the CR acquisition criterion, whereas a high percentage of those who performed 
above the identification threshold (perceiving words perfectly) did. These results are the opposite of the proportion obtained in Experiment 1. The objective consciousness concept considered to establish the perceptual threshold, regardless of the type of task used, is not sufficiently capable of explaining all the data, as it generates paradoxical results. The usefulness of this concept is restricted to measuring the limits of detection and identification thresholds.

The task of measuring a participant's consciousness seems to be the most relevant factor influencing the appearance or nonappearance of unconsciously-processed information effects. Contradictions in studies about subliminal perception might be explained by the different tasks used. Hence, when the identification threshold was used, the effects of unconsciously-processed information did not appear (Cheesman \& Merikle, 1984; Merikle, 1982; Reingold \& Merikle, 1988), and when the detection threshold was used, the effects of unconsciously-processed information did appear (Dagenbach et al., 1989; Marcel, 1983a). For the same reason, Öhman and his team might have failed to achieve unconscious conditioning to neutral stimuli. They usually used a threshold of a similar length $(30 \mathrm{~ms})$ to the average identification threshold obtained in our experiment (Öhman \& Soares, 1993, 1998; Soares \& Öhman, 1993a, 1993b).

\section{Analysis of the Two Experiments}

\section{Initial Similarity of Experimental Groups}

After carrying out the corresponding ANOVA on the 23 personality variables measured before the experimental phase (16PF, Intelligence, Attention, and Locus of Control), no statistically significant differences were identified among any of the experimental groups for the two experiments (taken separately as well as jointly). This suggests that random distribution of participants generated similar groups (see Table 3).

Table 3

Personality Variables: Means and Standard Deviations of the Experimental Groups for the Two Experiments (Taken Separately as well as Jointly)

\begin{tabular}{|c|c|c|c|c|c|c|c|c|c|c|c|c|c|c|}
\hline \multirow{3}{*}{ Variable } & \multicolumn{4}{|c|}{ EXP 1} & \multicolumn{4}{|c|}{ EXP 2} & \multicolumn{6}{|c|}{ EXP 1 and 2} \\
\hline & \multicolumn{2}{|c|}{ Unconscious } & \multicolumn{2}{|c|}{ Conscious } & \multicolumn{2}{|c|}{ Unconscious } & \multicolumn{2}{|c|}{ Conscious } & \multicolumn{2}{|c|}{ Null Perc. } & \multicolumn{2}{|c|}{ Confused Perc. } & \multicolumn{2}{|c|}{ Clear Perc. } \\
\hline & $M$ & $S D$ & $M$ & $S D$ & $M$ & $S D$ & $M$ & $S D$ & $M$ & $S D$ & $M$ & $S D$ & $M$ & $S D$ \\
\hline INTELL & 31.39 & 5.782 & 30.67 & 5.531 & 31.42 & 3.942 & 31.83 & 4.239 & 31.39 & 5.782 & 30.97 & 4.895 & 31.83 & 4.239 \\
\hline ATTEN & 46.00 & 6.059 & 48.11 & 6.398 & 49.17 & 5.982 & 51.42 & 6.244 & 46.00 & 6.059 & 48.53 & 6.152 & 51.42 & 6.244 \\
\hline LOCUS & 68.78 & 10.167 & 69.33 & 11.722 & 70.50 & 11.611 & 60.50 & 13.860 & 68.78 & 10.167 & 69.80 & 11.490 & 60.50 & 13.860 \\
\hline A & 8.22 & 2.290 & 8.56 & 2.549 & 8.33 & 1.923 & 7.67 & 2.348 & 8.22 & 2.290 & 8.47 & 2.285 & 7.67 & 2.348 \\
\hline B & 5.33 & 1.237 & 5.06 & 1.662 & 6.58 & 1.379 & 5.50 & 1.168 & 5.33 & 1.237 & 5.67 & 1.709 & 5.50 & 1.168 \\
\hline $\mathrm{C}$ & 6.67 & 2.425 & 6.00 & 2.765 & 7.00 & 1.907 & 6.67 & 2.871 & 6.67 & 2.425 & 6.40 & 2.472 & 6.67 & 2.871 \\
\hline $\mathrm{E}$ & 6.00 & 2.223 & 6.44 & 2.175 & 6.67 & 2.535 & 7.58 & 1.621 & 6.00 & 2.223 & 6.53 & 2.285 & 7.58 & 1.621 \\
\hline $\mathrm{F}$ & 7.00 & 2.351 & 7.22 & 1.801 & 5.67 & 2.498 & 7.33 & 2.015 & 7.00 & 2.351 & 6.60 & 2.207 & 7.33 & 2.015 \\
\hline G & 8.28 & 2.697 & 8.17 & 2.036 & 8.42 & 2.610 & 7.75 & 2.958 & 8.28 & 2.697 & 8.27 & 2.243 & 7.75 & 2.958 \\
\hline $\mathrm{H}$ & 5.56 & 2.617 & 5.67 & 2.635 & 6.42 & 2.644 & 6.00 & 2.558 & 5.56 & 2.617 & 5.97 & 2.619 & 6.00 & 2.558 \\
\hline I & 5.94 & 2.733 & 5.67 & 2.142 & 4.50 & 2.236 & 5.58 & 2.353 & 5.94 & 2.733 & 5.20 & 2.219 & 5.58 & 2.353 \\
\hline $\mathrm{L}$ & 5.56 & 2.064 & 4.89 & 1.997 & 5.58 & 1.881 & 5.17 & 1.528 & 5.56 & 2.064 & 5.17 & 1.949 & 5.17 & 1.528 \\
\hline M & 5.06 & 2.313 & 4.72 & 2.675 & 4.08 & 2.610 & 5.50 & 2.939 & 5.06 & 2.313 & 4.47 & 2.623 & 5.50 & 2.939 \\
\hline $\mathrm{N}$ & 3.39 & 2.118 & 3.78 & 2.045 & 3.33 & 2.146 & 3.75 & 2.050 & 3.39 & 2.118 & 3.60 & 2.061 & 3.75 & 2.050 \\
\hline $\mathrm{O}$ & 6.67 & 2.590 & 6.89 & 2.349 & 7.33 & 2.015 & 6.83 & 2.887 & 6.67 & 2.590 & 7.07 & 2.196 & 6.83 & 2.887 \\
\hline Q1 & 7.83 & 2.229 & 6.06 & 2.754 & 7.33 & 1.723 & 7.83 & 2.167 & 7.83 & 2.229 & 6.57 & 2.445 & 7.83 & 2.167 \\
\hline Q2 & 3.89 & 2.398 & 3.83 & 1.948 & 4.00 & 1.651 & 3.67 & 2.640 & 3.89 & 2.398 & 3.90 & 1.807 & 3.67 & 2.640 \\
\hline Q3 & 6.78 & 2.130 & 6.22 & 2.184 & 6.83 & 1.899 & 6.33 & 2.103 & 6.78 & 2.130 & 6.47 & 2.063 & 6.33 & 2.103 \\
\hline Q4 & 6.61 & 2.404 & 6.94 & 2.940 & 7.08 & 2.811 & 7.17 & 2.623 & 6.61 & 2.404 & 7.00 & 2.841 & 7.17 & 2.623 \\
\hline QI & 5.978 & 1.4111 & 6.028 & 1.4712 & 6.192 & 1.2479 & 6.017 & 1.6895 & 5.978 & 1.4111 & 6.093 & 1.3661 & 6.017 & 1.6895 \\
\hline QII & 6.139 & 1.6720 & 6.228 & 1.3208 & 6.042 & 1.4324 & 6.267 & 1.8396 & 6.139 & 1.6720 & 6.153 & 1.3452 & 6.267 & 1.8396 \\
\hline QIII & 5.350 & 1.4509 & 5.117 & 1.5120 & 5.575 & 1.6344 & 5.000 & 1.5380 & 5.350 & 1.4509 & 5.300 & 1.5510 & 5.000 & 1.5380 \\
\hline QIV & 5.978 & 1.7605 & 6.167 & 1.1882 & 6.917 & 1.6525 & 6.908 & .9643 & 5.978 & 1.7605 & 6.467 & 1.4153 & 6.908 & .9643 \\
\hline
\end{tabular}

Note. Personality variables are: Intelligence, Attention, Locus of Control and 16PF. Null Perception = below detection threshold. Confused Perception $=$ above detection threshold and below identification threshold. Clear Perception $=$ above identification threshold . 


\section{CR Acquisition and Consciousness}

The thresholds used in both experiments allow differentiation of consciousness, as defined by three levels of perception: (a) clear perception: participants who perceived stimuli clearly (above identification threshold); (b) confused perception: participants who perceived something but were unable to identify it (below identification threshold and above detection threshold); and (c) null perception: participants who did not discriminate whether or not there was something on the screen (below detection threshold). As can be seen in Figure 2, data show that optimal settings for conditioning are reached at both the clear (58\% CR acquisition) and the null level (50\% CR acquisition), whereas conditioning is difficult to acquire at the confused level (11\% CR acquisition).

There were no statistically significant differences in CR acquisition among participants who were acting at the clear perception level and participants who were acting at the null perception level, according Fisher's exact test, $p=.53$. On the other hand, there were significant differences between participants who were acting at the confused perception level and those who were acting at the clear perception level, $p=$ .003 , and the null perception level, $p=.03$. The percentage of participants who acquired the $\mathrm{CR}$ at the confused perception level was significantly lower than that of participants who acquired the $\mathrm{CR}$ at the clear and null perception levels.

\section{Differences Between Conscious and Unconscious Conditioning}

If both experiments are taken into account, differences between conscious and unconscious conditioning may be established. Conscious conditioning is understood as that which has been produced at the clear perception level, and unconscious conditioning is that which has been produced at the null perception level. Conditioning that occurred at the confused perception level will be ignored for the purpose of these comparisons. Thus, there were no statistically significant differences between conscious and unconscious conditioning regarding the number of trials needed to reach the $\mathrm{CR}$ acquisition criterion, $U=9.5, p=.39$, or the regularity of reaching that criterion (Fisher's exact test, $p=$

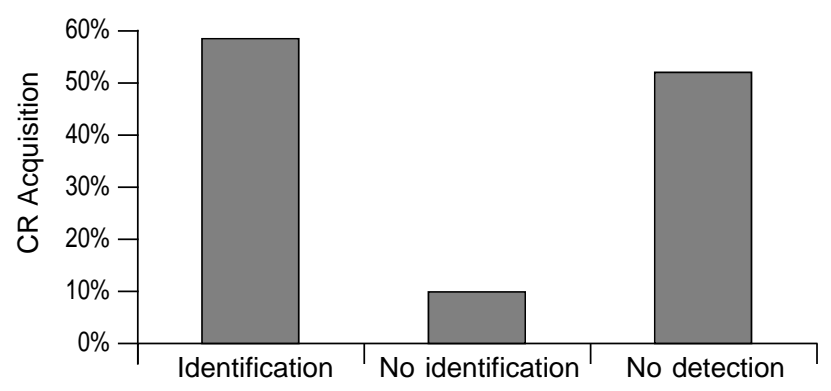

Figure 2. Percentage of participants who reached the CR acquisition criterion ( $\mathrm{Y}$ axis), according to each visual perceptual threshold ( $\mathrm{X}$ axis), in Experiments 1 and 2 together.
.46). Nevertheless, there was a trend for participants who were acting at a conscious level to need fewer trials to reach the $\mathrm{CR}$ acquisition criterion $(M=33, S D=16$, Max. $=60$, Min. = 11) than those acting at an unconscious level $(M=$ $47, S D=27$, Max. = 84, Min. = 23). In addition, participants who were acting at a conscious level reached the CR acquisition criterion with greater regularity (the two CRs appeared in two consecutive trials in $71 \%$ of cases) than participants acting at an unconscious level (the two CRs appeared in two consecutive trials in $28 \%$ of cases).

With regard to the personality variables measured, a single statistically significant difference emerged between conscious and unconscious conditioning: It was in the $\mathrm{E}$ factor of the 16PF, $U=3, p=.03$. Participants who reached the $\mathrm{CR}$ acquisition criterion unconsciously were more submissive and conformist than those who reached it consciously.

\section{Differences in Personality Variables Between Participants Who Acquired the CR and Those Who Did Not}

Within the null perception group, statistically significant differences between participants who reached the CR acquisition criterion and those who did not were found in two factors of the 16PF: QIII, $U=0, p=.0$; and Q3, $U=1, p=$ .04. Participants who reached the $\mathrm{CR}$ acquisition criterion accepted few obligations, were unconcerned about rules, and acted in a spontaneous, lively, and impulsive way, according to their needs (QIII factor). They expressed few concerns about controlling their emotions, behavior, and image (Q3 factor).

Within the clear perception group, there was just one statistically significant difference between participants who reached the CR acquisition criterion and those who did not, in Factor I of the 16PF, $U=4.5, p=.03$. Participants who reached the $\mathrm{CR}$ acquisition criterion were more realistic, practical, and skeptical about subjective issues than those who did not reach the CR acquisition criterion.

\section{Relationship Between Subjective Consciousness of CS-US Contingency and Perceptual Threshold}

The questionnaire completed by participants after the experiments indicated the absence of bias in their performance. One of the items from this questionnaire asked whether the participant had associated anything with the electrical shock and, if so, with what? The results showed three types of participants: (a) participants who did not associate the US with anything; (b) participants who made the wrong association; and (c) participants who identified the CS-US contingency correctly, albeit partially (for example, based on the size or the initial letter of the CS+ word). Table 4 shows the percentage of participants within each perception level who made each kind of association and the percentage of participants who acquired the CR according to the type of CS-US association they made. 
Table 4

Percentage of Participants Who Established Each CS-US Association According to Their Perception Level

\begin{tabular}{lccc}
\hline \multirow{2}{*}{$\begin{array}{c}\text { CS-US } \\
\text { Association }\end{array}$} & \multicolumn{3}{c}{ Perception } \\
\cline { 2 - 4 } & Null & Confused & Clear \\
\hline None (28\%) & $62.5 \%$ & $61 \%$ & $25 \%$ \\
Incorrect (8\%) & $37.5 \%$ & $32 \%$ & $8 \%$ \\
Correct (60\%) & $0 \%$ & $7 \%$ & $67 \%$ \\
\hline
\end{tabular}

Note. Null Perception = below detection threshold. Confused Perception $=$ above detection threshold and below identification threshold. Clear Perception $=$ above identification threshold.

a The percentage of participants who acquired the CR, according to the type of CS-US association they made, appears in brackets.

None of the participants from the null perception level identified the CS-US contingency correctly. On the other hand, $40 \%$ of the participants who identified the CS-US contingency did not acquire the CR, and $36 \%$ of the participants who did not identify the CS-US contingency acquired the CR. This suggests that subjective consciousness of the CS-US contingency is not a necessary or sufficient condition for conditioning. Even so, consciousness of the CS-US contingency had differential effects on the probability of $\mathrm{CR}$ acquisition (according to the corresponding contingency table $\left.{ }^{2}, c^{2}(2, N=48)=7.52, p=.02\right)$. The percentage of participants who reached the CR acquisition criterion was significantly higher among participants who identified the CS-US contingency than among those who made the wrong association according to Fisher's exact test, $p=.01$. Significant differences were not observed between participants who identified the CS-US contingency and those who made no association, $p=.08$, nor between the latter and participants who made the wrong association, $p=.15$.

\section{Effect Size of Consciousness Concepts in CR Acquisition}

Out of the three consciousness concepts, perceptual threshold (identification, non-identification, and non-detection), subjective consciousness (what is associated with the US), and objective consciousness (whether the number of correct responses is above or below random), the perceptual threshold seems to explain the results of the CR acquisition best, with regard to contingency coefficient values. The contingency coefficient between $\mathrm{CR}$ acquisition and the perceptual threshold was $.436, p=.004$, subjective consciousness was $.368, p=$
.02 , and objective consciousness was $.024, p=.87$. If these values are transformed into percentages, they can be compared, regardless of the number of cells in each contingency table ${ }^{3}$ (see Sachs, 1978). The relationship between CR acquisition and the perceptual threshold was $62 \%$, subjective consciousness was $52 \%$, and objective consciousness was $3.4 \%$.

\section{General Discussion}

\section{Consciousness and CR Acquisition}

The results of the two experiments about the role that consciousness plays in CR acquisition suggest that consciousness of the CS-US contingency is not necessary for CR acquisition by the ANS, as postulated by some authors (Davey, 1992a). Fifty percent of the participants who failed to discriminate between a blank screen and one with a word anticipated the US when a CS+ word was presented. Stimuli presented below the detection threshold seem to be processed and associated with biologicallyrelevant stimuli for humans (shock), so that after some trials, their presence stimulates an emotional response.

A new result that emerges from this research is that unconscious conditioning was possible with neutral stimuli. To date, in several studies, Öhman and colleagues obtained conditioned ANS responses to fear-relevant stimuli but not to visually-masked neutral stimuli (Esteves et al., 1994; Öhman \& Soares, 1998). The discrepancy with our results could be attributed to the different experimental methodology used. In our study, perceptual thresholds were established individually, and consciousness was measured simultaneously with stimulus presentation throughout the experiment. Furthermore, a detection threshold was used in conjunction with an identification threshold, which makes it much more restrictive and discourages participants from attempting to guess what they see. Lastly, in the acquisition phase, many trials were carried out, and the SCR with the CS+ was compared in each trial to the SCR with the CS-, in order to determine when the CR appeared.

\section{Conscious Conditioning versus Unconscious Conditioning}

Differentiating, at a theoretical level, two processes that are exactly the same in practice poses a problem (Brody, 1989; Shanks, 2002). It is not sufficient to guarantee nonconscious perception of stimuli. If unconscious conditioning

\footnotetext{
2 The contingency table does not fulfill the requirement that no more than $20 \%$ of the cells may have expected values of less than 5 , but this is the only way to obtain an index of the joint effect of the three categories.

3 The tables of perceptual threshold and subjective consciousness do not fulfill the requirement that no more than $20 \%$ of cells may have expected values of less than 5 .
} 
is identical to conscious conditioning, the inability of participants to discriminate stimuli could simply be a methodological device that would not justify such a distinction. Measures taken to register differences between the two processes did not provide any significant results.

In the extinction phase, no differences appeared between the two processes. The CR acquired consciously or unconsciously disappeared quickly in both cases. This result is common in studies on conditioning to subliminal visual stimuli (see Experiment 1 in Öhman, Dimberg, \& Esteves, 1989). Two factors explain this phenomenon. Firstly, the $\mathrm{CR}$ was recently acquired and had hardly been reinforced. Secondly, participants were explicitly informed about US withdrawal to accelerate CR extinction (Dawson \& Grings, 1968; Soares \& Öhman, 1993a). We now know about the unsuitability of the two circumstances coinciding, but extinction of an unconsciously-acquired CR was expected to be slower than extinction of a consciously-acquired CR, regardless of the information participants had.

It is necessary to verify the trends identified with regard to the larger number of trials needed to reach the CR acquisition criterion and the lower regularity of this acquisition in unconscious conditioning. The number of participants who reached the $\mathrm{CR}$ acquisition criterion (consciously and unconsciously) would have to be increased in order to use more powerful tests. The detection of differences in the number of trials needed and in the way to reach the $\mathrm{CR}$ acquisition criterion would require an increase in the number of trials for the acquisition phase and the CRs needed to reach the $\mathrm{CR}$ acquisition criterion, respectively. This would mean that the $\mathrm{CR}$ was more consolidated, thus delaying extinction. Furthermore, increasing the length of this phase would involve reducing the threshold establishment phase in order to avoid prolonging the experiment.

As the participation of consciousness seems to influence CR acquisition, it may be premature to consider consciousness as merely the result of unconscious processing, as some authors propose (Jackendoff, 1987; Velmans, 1991). Our results indicate that when conditioning is conscious, it tends to be acquired more quickly and more regularly than when it is unconscious.

According to the personality variables measured, participants who acquire the CR unconsciously adapt to circumstances more easily, because they fail to discover why the shock appears, and they are more spontaneous and adopt a passive attitude more easily than those who acquire the CR consciously. These characteristics are related to an attitude that facilitates the appearance of unconsciously-processed information effects, and therefore of unconscious conditioning (Dagenbach et al., 1989; Dixon, 1981; Landis et al., 1992; Marcel, 1983a; Snodgrass et al., 1993; Van Selst \& Merikle, 1993).

\section{Measure of Consciousness}

The results obtained in the two experiments indicate a high ISI variability among participants. If the same threshold were used for all participants, there would be a high risk of some participants perceiving clearly and others not perceiving anything, so that the results would become less reliable. These results support the criterion held by some authors whereby the individual setting of perceptual thresholds is a necessary condition for guaranteeing perception without consciousness (Cheesman \& Merikle, 1984; Holender, 1986; Merikle, 1982; Reingold \& Merikle, 1988).

The instability of some participants' perceptual thresholds during the experiment (whereby participants responded correctly above random when acting below the conscious threshold) underlines the importance of using simultaneous measures (trial-by-trial) of consciousness, as the most reliable way of guaranteeing that participants are working at an unconscious level. This instability could be a consequence of individual differences ${ }^{4}$ (vision, concentration, having slept well, etc.), chance (a highly restrictive criterion was used), practice (Wolford, Marchak, \& Hughes, 1988), increased alertness due to US presence, the break between phases, or a combination of some or all of these. However, as ISI stability is greater with identification judgments $(84 \%)$ than with detection judgments (45\%), it cannot be explained only by these variables, because all were equally present in the two experiments. Another possible explanation is the different type of task used in each experiment. Thus, the instability of detection thresholds could be attributed to the influence of unconscious information that increases performance above random. Direct measures of consciousness could be affected by unconscious information processing, as occurs in priming and in unconscious conditioning tasks (Berry, 1994; Bowers, 1984; Reber, 1989). On the other hand, the stability of identification thresholds, which fosters a search for and interpretation of consciously-perceived signals, could be a consequence of the limited capacity of conscious activity, which cannot be extended by effort (Mandler, 1992).

Although consciousness is a subjective experience, using a subjective measure of consciousness does not seem fruitful, as when participants say that they cannot see anything, with a certain margin of error due to benevolence or to participants' uncertainty when valuing their own perception, one can speculate about unconscious perception, but one cannot guarantee that participants have stopped attempting to discriminate the little they can see. The use of the objective detection threshold is a better guarantee that most participants relax their conscious activity as there are no clues or signals to interpret.

\footnotetext{
4 Within unconscious groups, there was only one significant difference $(U=61.5, p=.046)$ in the C Factor (Emotional Stability) of the 16PF between participants who were excluded in the CR acquisition phase, as their perception was above random $(n=12, M=5.8$, $S D=2.3)$, and participants who remained working at a nonconscious level $(n=18, M=7.4, S D=1.9)$.
} 


\section{Conscious and Unconscious Interaction}

Many authors argue that conscious activity takes precedence over unconscious activity, especially in unknown situations (Pribram \& Martín, 1995; Rumelhart, 1977; Shiffrin \& Schneider, 1977). Thanks to this precedence of conscious activity, we find our behavior appropriate. Our behavior would be most disconcerting if unconscious activity took precedence over conscious activity. Our behavior would be independent of our own decisions, and of our perception of ourselves and the world. This precedence of conscious activity would explain the difficulty in achieving conditioning at the confused perception level, as conscious processing of the "remaining" stimuli would inhibit the processing of unconscious information (Bornstein, 1992; Dagenbach et al., 1989; Dixon, 1981; Landis et al., 1992; Marcel, 1983a, 1983b; Snodgrass et al., 1993; Van Selst \& Merikle, 1993). Participants would be responding to speculations created by these "remnants," and not to real contingency (Berry, 1994; Hayes \& Broadbent, 1988; Reber, Kassin, Lewis, \& Cantor, 1980; Turner \& Fischler, 1993).

Unconscious information would be used in nonemergency situations, that is, mainly during moments of conscious passivity, or would, exceptionally, burst into consciousness totally or partially if it were relevant for the organism (Cherry, 1953). The way it bursts into consciousness would be through emotional reactions (UR or CR of Autonomous Nervous System) in most cases (Bower, 1981; Damasio, 1994; De Houwer et al., 1997; Frijda, 1988; Izard, 1977; Krosnick, Betz, Jussin, \& Lynn, 1992; Murphy \& Zajonc, 1993; Zajonc, 1980). Thus, although a stimulus would not be perceived consciously, if necessary, its unconscious processing could trigger an emotional reaction to prepare the organism to receive it and to find the necessary resources and the most appropriate response for resolving the situation (Katkin, 2001). In emergency situations, it is important for the organism's reaction to occur first, without the option of conscious activity blocking it. Preparing oneself to give a response is a higher priority than knowing what has caused the reaction. If our city's emergency systems (police, fire, ambulance services) did not respond to calls until they had received all the information about the situations facing them, they would probably be of no use to us. Their efficiency depends on rapid response. If they arrive late, what will have been the use of knowing exactly why they were called out? As the thalamus, the main route through which information is received from sensorial receptors, has a direct connection to the amygdala, which is related to emotional responses, it permits the latter to react $40 \mathrm{~ms}$ before the sensorial areas of the neocortex. This is because the thalamus has more complex connections to these areas of the neocortex, and this provides neurological support for the priority of an emotional response over a cognitive one (Iwata, LeDoux, Meeley, Arneric, \& Reis, 1986; LeDoux, 1990, 1996; LeDoux, Iwata, Cicchetti, \& Reis, 1988).
In Pavlovian conditioning, the CS is linked to the affective state generated by the US, and it does not seem reasonable that this mechanism is blocked when the processed stimulus is not a spider, a snake, or an angry face (for an alternative explanation, see Öhman, 2000). Our results show that masked neutral stimuli could be effective signals to be associated with and to activate emotional states in appropriate conditions.

\section{References}

Alphonse, J., \& Rodríguez, E. C. (1964). Frequency dictionary of Spanish words. London: Mouton.

Andrade, J. (1995). Learning during anaesthesia: A review. British Journal of Psychology, 86, 479-506.

Anstey, E., \& Pichot, P. (1955). Domino-48 Intelligence Test. Paris: Les Editions du Centre de Psychologie Appliquée. [Spanish version: Test de inteligencia Dominó 48. Madrid: TEA, 1990].

Baer, P. E., \& Fuhrer, M. J. (1982). Cognitive factors in the concurrent differential conditioning of eyelid and skin conductance responses. Memory and Cognition, 10, 135-140.

Baeyens, F., Hermans, D., \& Eelen, P. (1993). The role of CS-US contingency in human evaluative conditioning. Behaviour Research and Therapy, 31, 731-737.

Baron, A., \& Galizio, M. (1983). Instrumental control of human operant behavior. Psychological Record, 33, 495-520.

Bechara, A., Damasio, H., Tranel, D., \& Damasio, A. R. (1997). Deciding advantageously before knowing the advantageous strategy. Science, 275, 1293-1294.

Bechara, A., Tranel, D., Damasio, H., Adolphs, R., Rockland, C., \& Damasio, A. R. (1995). Double dissociation of conditioning and declarative knowledge relative to the amygdala and hippocampus in humans. Science, 269, 1115-1118.

Berry, D. C. (1994). Implicit learning: Twenty-five years on. A tutorial. In C. Umiltá \& Ch. Moscovitch (Eds.), Attention and performance $X V$ : Conscious and non-conscious information processing. Cambridge, MA: MIT Press.

Bornstein, R. F. (1992). Inhibitory effects of awareness on affective responding: Implications for the affect-cognition relationship. In M. S. Clark (Ed.), Emotion. Review of personality and social psychology (Vol. 13, pp. 235-255). Newbury Park, CA: Sage.

Bower, G. H. (1981). Mood and memory. American Psychologist, $36,129-148$.

Bowers, K.S. (1984). On being unconsciously influenced and informed. In Bowers, K.S. \& Meinchenbaum, D. (Eds.), The unconscious reconsidered. New York: Wiley.

Broadbent, D. E., Fitzgerald, P., \& Broadbent, H. P. (1986). Implicit and explicit knowledge in the control of complex systems. British Journal of Psychology, 77, 35-50.

Brody, N. (1989). Unconscious learning of rules: Comment on Reber's analysis of implicit learning. Journal of Experimental Psychology: General, 118, 236-238.

Catell, R.B. (1949). Sixteen Personality Factor Questionnaire (16 PF). Champaign, IL: IPAT. [Spanish version: Cuestionario factorial de personalidad 16 PF. Madrid: TEA, 1988]. 
Cheesman, J., \& Merikle, P. M. (1984). Priming with and without awareness. Perception and Psychophysics, 36, 387-395.

Cherry, C. (1953). Some experiments on the reception of speech with one and with two ears. Journal of the Acoustical Society of America, 25, 975-979.

Cohen, B. H. (1964). Role of awareness in meaning established by classical conditioning. Journal of Experimental Psychology, 67, 373-378.

Corteen, R. S., \& Wood B. (1972). Autonomic responses to shockassociated words in an unattended channel. Journal of Experimental Psychology, 94, 308-313.

Dagenbach, D., Carr, T. H., \& Wilhelmsen, A. L. (1989). Taskinduced strategies and near-threshold priming: Conscious influences on unconscious perception. Journal of Memory and Language, 28, 412-443.

Damasio, A. R. (1994). Descartes' error. Emotion, reason and the human brain. New York: Putnam.

Daum, I., Channon, S., \& Canavar, A. (1989). Classical conditioning in patients with severe memory problems. Journal of Neurology and Neurosurgery Psychiatry, 52, 47-51.

Davey, G. C. L. (1992a). Classical conditioning and the acquisition of human fears and phobias: A review and synthesis of the literature. Advances of Behavior Research and Therapy, 14, 29-66.

Davey, G. C. L. (1992b). An expectancy model of laboratory preparedness effects. Journal of Experimental Psychology: General, 121, 24-40.

Davey, G. C. L. (1994). Is evaluative conditioning a qualitatively distinct form of classical conditioning? Behavior Research and Therapy, 32, 307-310.

Dawson, M. E., \& Grings, W. W. (1968). Comparison of classical conditioning and relational learning. Journal of Experimental Psychology, 76, 227-231.

De Houwer, J., Hendrickx, H., \& Baeyens, F. (1997). Evaluative learning with «subliminally» presented stimuli. Consciousness and Cognition: An International Journal, 6, 87-107.

Debner, J. A, \& Jacoby, L. L. (1994). Unconscious perception: Attention, awareness, and control. Journal of Experimental Psychology: Learning, Memory and Cognition, 20, 304-317.

Dixon, N. F. (1981). Preconscious processing. New York: Wiley.

Esteves, F., \& Öhman, A. (1993). Masking the face: Recognition of emotional facial expressions as a function of the parameters of backward masking. Scandinavian Journal of Psychology, 34, 1-18.

Esteves, F., Parra, C., Dimberg, U., \& Öhman, A. (1994). Nonconscious associative learning: Pavlovian conditioning of skin conductance responses to masked fear-relevant facial stimuli. Psychophysiology, 31, 375-385.

Frijda, N. H. (1988). The laws of emotion. American Psychologist, 43, 349-358.

Fuhrer, M. J., \& Baer, P. E. (1980). Cognitive factors in CS-UCS interval effects in the differential conditioning and extinction of skin conductance responses. Biological Psychology, 10, 283-298.

Gabrieli, J.D., McGlinchey B.R., Carrillo, M.C., Gluck, M.A., Cermack, L.S., \& Disterhoft, J.F. (1995). Intact delay-eyeblink classical conditioning in amnesia. Behavioral Neuroscience, 109, 819-827.
Ghoneim, M. M., Block, R. I., \& Fowles, D. C. (1992). No evidence of classical conditioning of electrodermal responses during anesthesia. Anesthesiology, 76, 682-688.

Grant, D. A. (1973). Cognitive factors in eyelid conditioning. Psychophysiology, 10, 75-81.

Greenspoon, J. (1963). Reply to Spielberger and De Nike: “Operant conditioning of plural nouns: A failure to replicate the Greenspoon effect". Psychological Reports, 12, 29-30.

Hayes, N. A., \& Broadbent, D. E. (1988). Two modes of learning for interactive tasks. Cognition, 28, 249-276.

Hefferline, R. J., \& Keenan, B. (1961). Amplitude-induction gradient of a small operant in an escape-avoidance situation. Journal of the Experimental Analysis of Behavior, 4, 41-43.

Holender, D. (1986). Semantic activation without conscious identification in dichotic listening, parafoveal vision, and visual masking: A survey and appraisal. Behavioral and Brain Sciences, 9, 1-66.

Isen, A., Shalker, T., Clark, M., \& Karp, L. (1978). Affect, accessibility of material in memory, and behavior: A cognitive loop? Journal of Personality and Social Psychology, 36, 1-12.

Iwata, J., LeDoux, J. E., Meeley, M. P., Arneric, S., \& Reis, D. J. (1986). Intrinsic neurons in the amygdaloid field projected to by the medial geniculate body mediate emotional responses conditioned to acoustic stimuli. Brain Research, 383, 195-214.

Izard, C. E. (1977). Human emotions. New York: Plenum Press.

Jackendoff, R. (1987). Consciousness and the computational mind. Cambridge, MA: MIT Press.

Jelicic, M., Bonke, B., Wolters, G., \& Phaf, R. H. (1992). Implicit memory for words presented during anaesthesia. European Journal of Cognitive Psychology, 4, 71-80.

Katkin, E. (2001): Nonconscious fear conditioning, visceral perception, and the development of gut feelings. Psychological Science, 12, 366-370.

Krosnick, J. A., Betz, A. L., Jussin, L. J., \& Lynn, A. R. (1992). Subliminal conditioning of attitudes. Personal and Social Psychology Bulletin, 18, 152-162.

Landis, T., Christen, L., \& Graves, R. (1992). Dissociated hemispheric and stimulus effects upon affective choice and recognition. International Journal of Neuroscience, 62, 81-87.

Lazarus, R. S., \& Mc Cleary, R. A. (1951). Automatic discrimination without awareness: A study of subception. Psychological Review, 58, 113-122.

LeDoux, J. E. (1990). Information flow for sensation to emotion: Plasticity in the neural computation of stimulus values. In M. Gabriel \& J. Moore (Eds.), Neurocomputation and learning: Foundation and adaptive networks (pp. 3-52). Cambridge, MA: MIT Press.

LeDoux, J. E. (1996). The emotional brain: The mysterious underpinnings of emotional life. New York: Simon \& Schuster.

LeDoux, J. E., Iwata, J., Cicchetti, P., \& Reis, D. J. (1988). Different projections of the central amygdaloid nucleus mediate autonomic and behavioral correlates of conditioned fear. Journal of Neuroscience, 8, 2517-2529.

Lee, Y. (1995). Effects of learning contexts on implicit and explicit learning. Memory and Cognition, 23, 723-734. 
Levey, A. B., \& Martin, I. (1975). Classical conditioning of human «evaluative» responses. Behavior Research and Therapy, 13, 221-226.

Likken, D. T. (1972). Range correction applied to Heart rate and to GSR data.Psychophysiology, 9, 373-379.

Likken, D. T., \& Venables, P. H. (1971). Direct measurement of skin conductance: A proposal for standardization. Psychophysiology, 8, 656-672.

Lowe, C. F. (1983). Radical behaviorism and human psychology. In G. C. L. Davey (Ed.), Animal models of human behavior (pp. 71-93). Chichester, UK: Wiley.

Mandler, G. (1992). Toward a theory of consciousness. In H. Geissler, S.W. Link, \& J.T. Townsend (Eds.), Cognition, information processing and psychophysics (pp. 43-65). Hillsdale, NJ: Erlbaum.

Marcel, A. J. (1983a). Conscious and unconscious perception: Experiments on visual masking and word recognition. Cognitive Psychology, 15, 197-237.

Marcel, A. J. (1983b). Conscious and unconscious perception: An approach to the relations between phenomenal experience and perceptual processes. Cognitive Psychology, 15 238-300.

Marcos, J. L. (1997). Condicionamiento clásico electrodérmico I y II. In J. L. Marcos (Coord.), Técnicas de condicionamiento humano (pp. 27-59). Madrid: Universitas.

Merikle, R M. (1982). Unconscious perception revisited. Perception and Psychophysics, 31, 298-301.

Merikle, P. M., Joordens, S., \& Stolz, J. A. (1995). Measuring the relative magnitude of unconscious influences. Consciousness and Cognition, 4, 422-439.

Meulemans, T., \& Van Der Linden, M. (1997). Does artificial grammar learning paradigm involve the acquisition of complex information? Psychologica Belgica, 37, 69-88.

Mighetto, D., \& Rosengren, P. (1984). Proyecto PE 77.Microfichas. Banco de datos de prensa española, 1977. Departamento de Lenguas Romances, Sección Lengua Española, Universidad de Göteborg.

Montare, A. (1992). Conditioning reaction time: Evidence for a process of conditioned automatization. Perceptual and Motor Skills, 75, 755-770.

Murphy, S. T., \& Zajonc, R. B. (1993). Affect, cognition and awareness: Affective priming with optimal and suboptimal stimulus exposures. Journal of Personality and Social Psychology, 64, 723-739.

Öhman, A. (1998). Emotional conditioning to masked stimuli: Expectancies for aversive outcomes following nonrecognized fear-relevant stimuli. Journal of Experimental Psychology: General, 127, 69-82.

Öhman, A. (2000). Unconscious emotion: Evolutionary perspectives, psychophysiological data and neuropsychological mechanisms. In Lane, R. \& Lynn, N. (Eds.), Cognitive neuroscience of emotion (pp. 296-327). London: Oxford University Press.

Öhman, A., Dimberg, U., \& Esteves, F. (1989). Preattentive activation of aversive emotions. In T. Archer \& L-G. Nilsson (Eds.), Aversion, avoidance and anxiety. Perspectives on aversively motivated behavior (pp. 169-193). Hillsdale, NJ: Erlbaum.
Öhman, A., \& Soares, J. (1993). On the automatic nature of phobic fear: Conditioning electrodermal responses to masked fearrelevant stimuli. Journal of Abnormal Psychology, 102, 121132.

Öhman, A., \& Soares, J. (1998). Emotional conditioning to masked stimuli: Expectancies for aversive outcomes following nonrecognized fear-relevant stimuli. Journal of Experimental Psychology, 127, 69-82.

Pelechano, V., \& Baguena, Mª J. (1983). Un cuestionario de Locus of Control (LUCAM). Análisis y Modificación de Conducta, 9, 5-46.

Perruchet, P., Gallego, J., \& Pacteau, C. (1992). A reinterpretation of some earlier evidence for abstractiveness of implicit implicitly acquired learning. Quarterly Journal of Experimental Psychology, 44A, 193-210.

Pribram, K. H., \& Martín, J. (1995). Cerebro y conciencia. Madrid: Díaz de Santos.

Prokasy, W. F., \& Ebel, H. C. (1967). Three components of the classically conditioned GSR in human subjects. Journal of Experimental Psychology, 73, 247-256.

Real Academia Española (1992). Diccionario de la lengua española ( $21^{\text {st }}$ ed.). Madrid: Espasa Calpe.

Reber, A. S. (1989). Implicit learning and tacit knowledge. Journal of Experimental Psychology: General, 118, 219-235.

Reber, A. S., Kassin, S. M., Lewis, S., \& Cantor, G. (1980). On the relationship between implicit and explicit modes in the learning of a complex rule structure. Journal of Experimental Psychology: Human Learning and Memory, 6, 492-502.

Reingold, E. M., \& Merikle, P. M. (1988). Using direct and indirect measures to study perception without awareness. Perception and Psychophysics, 44, 563-575.

Ross, L. E., Ferreira, M. C., \& Ross, S. M. (1974). Backward masking of conditioned stimuli: Effects on differential and single-cue classical conditioning performance. Journal of Experimental Psychology, 103, 603-613.

Rumelhart, D. E. (1977). An introduction to human information processing. New York: Wiley.

Sachs, L. (1969). Statistische Auswertungsmethoden. Berlin: Springer-Verlag. [Spanish version: Estadística aplicada. Madrid: Labor, 1978].

Shanks, D. R. (2002). Autonomic and eyeblink conditioning are closely related to contingency awareness: Reply to Wiens and Öhman (2002) and Manns et al. (2002). Journal of Experimental Psychology: Animal Behavior Processes, 28, 38-42.

Shanks, D. R., \& Dickinson, A. (1990). Contingency awareness in evaluative conditioning: A comment on Baeyens, Eelen, and Van den Bergh. Cognition and Emotion, 4, 19-30.

Shanks, D. R., \& Dickinson, A. (1991). Instrumental judgement and performance under variations in action-outcome contingency and contiguity. Memory and Cognition, 19, 353-360.

Shanks, D. R., Green, R. E., \& Kolodny, J. (1994). A critical examination of the evidence for nonconscious (implicit) learning. In C. Umiltá \& M. Moscovitch (Eds.), Attention and performance $X V$ : Conscious and non-conscious information processing. Cambridge, MA: MIT Press. 
Shiffrin, R. M., \& Schneider, W. (1977). Controlled and automatic human information processing: II. Perceptual learning, automatic attending and a general theory. Psychological Review, 84, 127-190.

Shimoff, E., Catania, A. C., \& Matthews, B. A. (1981). Uninstructed human responding: Sensitivity of low rate performance to schedule contingencies. Journal of the Experimental Analysis of Behavior, 36, 207-220.

Snodgrass, M., Shevrin, H., \& Kopka, M. (1993). The mediation of intentional judgments by unconscious perceptions: The influences of task strategy, task preference, word meaning, and motivation. Consciousness and Cognition, 2, 169-193.

Soares, J., \& Öhman, A. (1993a). Preattentive processing, preparedness and phobias: Effects of instruction on conditioned electrodermal responses to masked and non-masked fearrelevant stimuli. Behaviour Research and Therapy, 31, 87-95.

Soares, J., \& Öhman, A. (1993b). Backward masking and skin conductance responses after conditioning to nonfeared but fearrelevant stimuli in fearful subjects. Psychophysiology, 30, 460466.

Svartdal, F. (1992). Sensitivity to nonverbal operant contingencies: Do limited processing resources affect operant conditioning in humans? Learning and Motivation, 23, 383-405.

Svartdal, F., \& Mortensen, T. (1993). Effects of reinforcer value on sensitivity to non-verbal operant contingencies in humans. The Quarterly Journal of Experimental Psychology, 46A, 347-364.

Thurstone, L.L., \& Yela, M. (1968). Test of perceptions and differences-faces. Madrid: TEA.
Tranel, D., \& Damasio, A. R. (1993). The covert learning of affective valence does not require structures in hippocampal system or amygdala. Journal of Cognitive Neuroscience, 5, 7988.

Turner, C. W., \& Fischler, I. S. (1993). Speeded tests of implicit knowledge. Journal of Experimental Psychology. Learning, Memory and Cognition, 19, 1165-1177.

Van Selst, M., \& Merikle, P. M. (1993). Perception below the objective threshold. Consciousness and Cognition, 2, 194203.

Velmans, M. (1991). Is human information processing conscious? Behavioral and Brain Sciences, 14, 651-726.

Venables P. H., \& Christie, M. J. (1980). Electrodermal activity. In I. Martin \& P. H. Venables (Eds.), Techniques in psychophysiology (pp. 3-67). New York: Wiley.

Wolford, G., Marchak, F., \& Hughes, H. (1988). Practice effects in backward masking. Journal of Experimental Psychology: Human Perception and Performance, 14, 101-112.

Wong, P. S., Shevrin, H., \& Williams, W. J. (1994). Conscious and nonconscious processes: An ERP index of an anticipatory response in a conditioning paradigm using visually masked stimuli. Psychophysiology, 31, 87-101.

Zajonc, R. B. (1980). Feeling and thinking. Preferences need no inferences. American Psychologist, 35, 151-175.

Received August 14, 2002

Review Received January 13, 2004 Accepted January 27, 2004 